\title{
O movimento nacionalista industrializante no Brasil (1830-1930): uma análise a partir dos estudos de Nícia Vilela Luz
}

\author{
Rosalina Lima Izepão ${ }^{1}$ \\ Débora Giorno ${ }^{2}$
}

\begin{abstract}
RESUMO
Quando se trata da indústria brasileira, são inúmeros os estudos publicados no país. A industrialização nacional ocorreu num processo lento e gradual, fruto de muitas disputas e acordos entre os vários grupos de interesses agrários e industriais desde a fase colonial, passando pela imperial até o final da chamada I República, em 1930, quando este setor econômico começou, efetivamente, desabrochar. Considerando-se o exposto, no presente artigo, tem-se como objetivo analisar o movimento nacionalista industrializante, que se desenvolveu no Brasil, no período de 1830 a 1930, apresentado nos estudos de Nícia Vilela Luz, reunidos no livro "A luta pela industrialização do Brasil (1808 a 1930)". Metodologicamente, trata-se de uma pesquisa que pode ser caracterizada, por seus objetivos, como bibliográfico-descritiva. Apesar de o Brasil ter sido uma economia agrário-exportadora até 1930, os estudos de Luz mostram que sempre existiram no país, mesmo na fase colonial-mercantil, pessoas e grupos defensores da execução de políticas governamentais direcionadas ao desenvolvimento industrial. O fortalecimento deste movimento se deu a partir de 1875, em razão da crise agrária e suas consequências. Ao longo deste período se destacaram, nesta luta, segundo Luz (1961), pessoas como: Joaquim José Rodrigues, Antônio Felício dos Santos, Aristides de Queiroz, Serzedelo Correia, Amaro Cavalcanti e Roberto Simonsen. As políticas e ações desenvolvidas para o protecionismo industrial mais utilizadas, na época, foram tarifas alfandegárias, subsídios a determinados setores, além do uso do capital estrangeiro.
\end{abstract}

Palavras-chave: Brasil, indústria, nacional industrialismo.

\section{The nationalist industrializing movement in Brazil (1830-1930): an analysis from the studies of NíciaVilela Luz}

\begin{abstract}
When it comes to brazilian industry, there are numerous studies published in the country. The national industrialization took place in a slow and gradual process, the result of many disputes and agreements between the various agrarian and industrial interest groups from the colonial phase, through the imperial until the end of the first republican phase, in 1930, when this economic sector began, effectively bloom. Considering the above, this article aims to analyze the nationalist industrialist movement that developed in Brazil, from 1830 to 1930, based on the studies of NíciaVilela Luz. Methodologically, it was a research which can be characterized by its objectives as bibliographic-descriptive. Although Brazil was an agrarian-exporting economy until 1930, the results of this study showed that people and groups that advocated the implementation of government policies directed at industrial development always existed in the country, even in its colonial-mercantile phase. This movement was strengthened from 1875 onwards, due to the agrarian crisis and its consequences. During this period stood out in this fight, people like: Joaquim José Rodrigues, Antonio Felicio dos Santos, Aristides de Queiroz, Serzedelo Correia, Amaro Cavalcanti and Roberto Simonsen. The policies and actions developed for industrial protectionism that were most used at the time were customs tariffs, subsidies to certain sectors, and the use of foreign capital.
\end{abstract}

Key words: Brazil, industry, national industrialism.

\footnotetext{
${ }^{1}$ Doutora em História Econômica pela USP. Professora Associada do Departamento de Economia da Universidade Estadual de Maringá (UEM). E-mail: rlizepao@uem.br

${ }^{2}$ Historiadora. Graduada pela Universidade Estadual de Maringá (UEM). E-mail: debora_giorno@hotmail.com.
} 


\section{INTRODUÇÃO}

Existem inúmeras publicações a respeito da industrialização no Brasil, algumas, inclusive, consideradas obras clássicas. Os temas tratados são os mais variados e estendem-se desde os aspectos histórico-conceituais sobre indústria e industrialização, passando por todo processo histórico do seu nascimento, desenvolvimento, fases, estágios, modelos, políticas industriais governamentais, financiamentos, setores, polos e distritos industriais até as atuais controvérsias sobre a existência ou não no Brasil da chamada desindustrialização.

É fato que, a indústria brasileira só passou a desabrochar com mais de 100 anos de atraso em relação à fase clássica europeia, caracterizada, sobretudo, pela Revolução Industrial inglesa que data de 1750. Nesta época, o Brasil sequer era um Estado nacional, pois sua independência só viria ocorrer em 1822. O que, em si não seria problema, se considerarmos que a Alemanha, por exemplo, só completou a sua unificação em 1871. Portanto, 49 anos após o Brasil, e, ainda assim já era uma potência industrial em 1913, um ano antes de se ter início a I Guerra Mundial (1914-1918).

Diferente destes países, a industrialização brasileira ocorreu num processo lento e gradual, fruto de muitas lutas, disputas e acordos entre os vários grupos de interesses desde a fase mercantil colonial até o final da Primeira República, em 1930. Estas forças históricas foram, sem dúvida, determinantes para o seu desabrochar, embora com impressionante atraso em relação às economias desenvolvidas. Muitas foram as correntes teóricas, as práticas e as políticas que, em alguns momentos, geraram avanços no seu desenvolvimento, em outros atrasos e retrocessos. As raízes deste processo de lutas datam do Brasil colonial (1500/30$1822)^{3}$, estendem-se às fases do período Imperial, ou seja, I Reinado (1822-1831); Período Regencial (1831-1840) e II Reinado (1840-1889), passando pela I República (1889-1930).

Em todos os períodos citados existiram grupos e indivíduos que defenderam a indústria e a industrialização no Brasil, além de outros que se manifestaram contrários, pelas razões mais variadas, sendo a mais forte a questão agroexportadora. Considerando-se o exposto, no presente artigo, tem-se como objetivo analisar o movimento nacionalista industrializante, que se desenvolveu no Brasil, no período de 1830 a 1930; a partir das publicações de Nícia Vilela Luz na Revista de História, da Universidade de São Paulo (USP), reunidas no livro "A luta pela industrialização do Brasil (1808 a 1930), por sugestão do Professor João Cruz Costa. Segundo Costa apud Luz (1961, p. 5): "De fato, depois de haver lido os artigos que a autora publicou na Revista de História, julguei que seria um grave prejuízo para a compreensão de nossa história econômica perderem-se os seus artigos, tão ricos de material e de sugestões, nas páginas de uma revista especializada, nem sempre acessível a um público mais largo..."

O escopo do artigo é somente a corrente que defendia a industrialização, embora se saiba da existência de grupos contrários. Não se trata de um estudo sobre as origens da industrialização brasileira ou suas fases de desenvolvimento, mas, sim, dos antecedentes da sua história. Trata-se de uma época anterior às famosas controvérsias sobre a industrialização no Brasil dos anos 1930, protagonizadas, por exemplo, pelo industrialista Roberto Simonsen e o liberal Eugênio Gudin.

Metodologicamente, trata-se de uma pesquisa que pode ser caracterizada, por seus objetivos, como bibliográfico-descritiva, tendo como fonte principal o livro "A luta pela industrialização do Brasil (1808 a 1930), de Nícia Vilela Luz, publicado em 1961. Complementarmente, foram utilizados livros e artigos que tratam do tema.

\footnotetext{
${ }^{3} \mathrm{O}$ período que se estende de 1500 a 1530 compreende a fase de exploração do pau-brasil. As primeiras políticas portuguesas para garantir a posse territorial datam de 1534, com a criação das capitanias hereditárias que se estendiam do litoral até o limite geográfico estabelecido pelo tratado de Tordesilhas.
} 
O artigo encontra-se estruturado em quatro seções. Na primeira, tem-se essa Introdução; na segunda são apresentadas, de maneira sucinta, as credenciais de Nícia Vilela Luz e seu interesse pela história e o pensamento econômico brasileiro; na terceira, apresentam-se dados e argumentos utilizados por Luz (1961), que evidenciam a existência de um forte movimento nacional industrialista no Brasil, durante o período analisado. Ainda, nesta seção, destacam-se alguns dos representantes deste movimento, políticas propostas e alguns resultados. Na quarta e última seção, tem-se as Considerações Finais.

\section{NÍCIA VILELA LUZ E O SEU INTERESSE PELA HISTÓRIA E O PENSAMENTO ECONÔMICO BRASILEIRO}

Após graduar-se em História pela Faculdade de Filosofia, Letras e Ciências Humanas da Universidade de São Paulo (FFLCH/USP), no final dos anos 1950, Nícia Vilela Luz ingressou no curso de Pós-Graduação em História Americana na Universidade de Virginia, nos Estados Unidos. Ao retornar para o Brasil, iniciou sua carreira acadêmica como professora de História Americana, no Departamento de História da Universidade de São Paulo (USP). Em 1964 tornou-se Livre Docente na mesma Instituição, defendendo a tese intitulada "A política brasileira e as pretensões dos Estados Unidos na Amazônia: 1850 - 1855". (RIBEIRO, 2012)

De acordo com Ribeiro (2012), ainda nos anos 1960, Nícia Vilela Luz desenvolveu e publicou vários estudos sobre o Brasil, do período colonial até 1930, entre os quais se destacam os capítulos de livros "Inquietação Revolucionária no Sul: a Conjuração Mineira" e "As tentativas de industrialização no Brasil", bem como o livro "A Amazônia para os negros americanos: as origens de uma controvérsia internacional". Nesta obra, segundo Ribeiro (2012), a autora apresentou os resultados de suas pesquisas sobre a Amazônia, que já vinha desenvolvendo desde a elaboração da sua tese para defesa no concurso para Livre Docência no Departamento de História da USP. Para Ribeiro (2012), desde o final da década de 1950, Nícia Vilela Luz já se preocupava com questões que fugiam aos temas estudados pelos historiadores da USP. ${ }^{4}$

No entanto, a obra de Nícia Vilela Luz, de maior significado acadêmico é "A luta pela industrialização do Brasil (1808-1930)", publicada em 1961, cujo conteúdo será retrato, em parte, neste artigo. De acordo com Luz (1961), este livro apresenta resultados de uma pesquisa proposta, por meio de um projeto que seria executado por pesquisadores brasileiros e americanos, sob a orientação do Research Center in Entrepreneurial History da Universidade de Harvard. Tratava-se de uma pesquisa a ser realizada em grupos, em que cada grupo pesquisaria um setor da economia brasileira.

Mas o projeto não foi completamente concretizado. Apesar disto, Luz desenvolveu o estudo da parte que lhe coubera, tendo como tema "O nacionalismo econômico no Brasil". Na sequência, por orientação do professor Eurípedes Simões de Paula, Luz publicou, em vários artigos, os resultados das suas análises e conclusões na Revista de História, da USP. Posteriormente, aconselhada pelo professor João Cruz Costa, reuniu estes artigos e os compilou dando origem ao já mencionado livro. (O ESTADO DE SÃO PAULO, 1962; LUZ, 1961)

\footnotetext{
4 Ver LUZ, N. V. Inquietação revolucionária no Sul: a Conjuração Mineira. In: LINHARES, M. Y. e S.; TEIXEIRA, F. C. História Geral da Civilização Brasileira. São Paulo: Brasiliense, 1981. Tomo I. LUZ, N. V. As Tentativas de Industrialização no Brasil. In: HOLANDA, S. B. de. OBrasil Monárquico: declino e queda do Império. 5. ed. Rio de Janeiro: Bertrand Brasil S.A, 4 Vol. Coleção História Geral da Civilização Brasileira, 1995 , p. 28-41. LUZ, N. V. Amazônia para os negros americanos. Rio de Janeiro: Saga, 1968.
} 
Entende-se, neste artigo, que a leitura da obra "A luta pela industrialização do Brasil" de Nícia Vilela Luz é de suma importância para os que se interessam pela história econômica, mas, sobretudo, pela análise da evolução do pensamento econômico brasileiro. Citado e retratado em diversas obras de importantes pesquisadores da história do Brasil, além de artigos científicos, teses e dissertações, o livro apresenta uma rica análise historiográfica sobre a temática indústria/industrialização no país, seus principais agentes econômicos e políticos tanto da esfera privada, quanto governamental, além de representar um acervo significativo de informações, dados qualitativos e quantitativos, amplamente, utilizados ainda hoje nos mais diversos estudos acadêmicos.

Nesta obra, a historiadora traduz numa linguagem clara, objetiva e didática, como se desenvolveu no Brasil desde o período mercantil colonial até 1930, um pensamento econômico voltado diretamente para a defesa da industrialização brasileira, apesar do contexto histórico nacional ser desfavorável em razão da predominância dos interesses primário-exportadores.

\section{O MOVIMENTO NACIONALISTA INDUSTRIALIZANTE SEGUNDO LUZ (1808- 1930 $)^{5}$}

\subsection{O MERCANTILISMO COLONIAL, SUA SUPERAÇÃO E O DESPERTAR DO MOVIMENTO NACIONALISTA INDUSTRIALIZANTE NO FINAL DO IMPÉRIO}

Antes mesmo da chegada da Família Real no Brasil, em 1808, já existia nesta Colônia portuguesa, o desejo de promover a indústria local, por influência das transformações que estavam ocorrendo no ocidente europeu, fruto da I Revolução Industrial inglesa e que repercutiam na América. Segundo Luz (1961), com D. João VI surgem as primeiras tentativas de promoção da indústria no Brasil Colônia. Entre elas se destacam: a abertura dos portos às nações amigas "Inglaterra"; o alvará de 28 de abril de 1809, por meio do qual decretou diversas isenções, que favoreceriam o início do desenvolvimento industrial na Colônia, além de conceder auxílios aos primeiros introdutores de máquinas no território. O problema é que, dois anos após assinar este alvará, D. João VI passou a conceder privilégios à Grã-Bretanha na venda de suas mercadorias para o Brasil, entregando o mercado nacional aos ingleses num nacionalismo às avessas, conforme destacou a autora.

Esta exclusividade inglesa só terminaria em 1818, quando D. João VI assinou um novo decreto taxando todas as mercadorias estrangeiras no mesmo valor que eram tabelados os produtos ingleses, ou seja, $15 \%$, pondo em xeque o monopólio inglês. Após tornar-se independente, em 1822, foi mantida no Brasil, durante o Primeiro Reinado (1822-1831), a mesma estrutura tributária. Isso porque, neste período do Império, manteve-se uma economia baseada no comércio e na produção voltada para o setor agrário-exportador, tendo na alfandega sua principal fonte de renda. Assim, as principais ações governamentais foram centradas no controle das entradas e saídas de mercadorias, além de políticas direcionadas a coibir fraudes na arrecadação.

Outra medida mais significativa para o avanço da indústria nacional só viria em 1844, já no II Reinado quando se criou a tarifa Alves Branco, por meio da qual se passou a tributar em 30\% grande parte dos produtos estrangeiros. Esse valor, segundo Luz (1961), mostrou-se incapaz de causar uma proteção eficaz à indústria nacional. O Objetivo de Alves Branco seria melhorar a balança comercial brasileira e, assim, promover o desenvolvimento da indústria nacional. Com este objetivo, em 1843, um ano antes da criação da tarifa Alves Branco, foi

\footnotetext{
${ }^{5}$ Esta seção foi inteiramente escrita com base em Luz (1961).
} 
reorganizada a pauta alfandegária que decretou taxas de até $60 \%$ nos produtos similares aos nacionais que vinham de fora do Brasil.

Ocorre que, segundo Luz (1961), em meados do século XIX era grande e perceptível a existência de uma frente oposicionista às políticas de apoio à indústria nacional. Para atender os dois lados, ou seja, não abandonar os defensores da indústria, mas, também satisfazer aos interesses agrários; o governo imperial determinou o estabelecimento de direitos sobre matérias-primas importadas e a diminuição das taxas cobradas sob os gêneros de primeira necessidade de que se queixavam os interessados na lavoura monocultora. O objetivo, segundo os oposicionistas à indústria interna, era promover a exploração dos recursos naturais nacionais, ideia que prevaleceu, inclusive, durante a chamada Primeira República (1889-1930).

Estas tarifas passaram por algumas reformulações entre 1857 e 1860, estabelecendo medidas mais liberais para favorecer ainda mais os interesses da lavoura monocultora, principalmente, a redução nas taxas sobre gêneros de consumo, em geral. Segundo Luz (1961), os primeiros anos da década de 1860 foram de grande prosperidade econômica. Assim, apesar da Guerra do Paraguai (1864-1870) e da violenta crise comercial de 1864, a política fiscal do Império manteve-se intacta. Somente em 1867, foram aumentados alguns impostos. Paralelamente, crescia o número de defensores da indústria no Império, sob o argumento de que nenhuma nação poderia crescer, sem que executasse políticas econômicas a seu favor.

Um defensor da indústria foi o jornalista e político Joaquim José Rodrigues (18021872), o Visconde de Itaboraí que argumentava ser a industrialização de suma importância para a prosperidade econômica nacional. Filiado ao Partido Liberal, Rodrigues afirmava que os produtos da lavoura eram muito limitados e sujeitos às intempéries, por exemplo, chuvas fortes, granizo, geadas, pestes, secas e, por isso, dizia ser impossível uma nação exclusivamente agrícola prosperar como as nações manufatureiras. Contudo, para a autora, era muito difícil o desenvolvimento industrial no Brasil pela falta de recursos financeiros, de mão de obra qualificada, segurança e pela instabilidade política da época.

O protecionismo alfandegário, estabelecido desde a vinda da Família Real para o Brasil, em 1808, sempre se mostrou ineficaz na promoção do crescimento industrial. Em 1852, por exemplo, já no II Reinado, existiam no Brasil imperial 21 fábricas nacionais de chapéus, mas a tarifa de $30 \%$ para importação deste produto não lhes favorecia. Além disto, segundo Luz (1961), nem sempre os valores cobrados correspondiam aos valores reais das mercadorias, o que basicamente significa que nem sempre eram taxados em exatos $30 \%$ e, sim, em uma média que variava em torno de $20 \%$. O fato é que não existiram políticas governamentais que auxiliassem, efetivamente, o desenvolvimento da indústria nacional até 1875. As poucas indústrias, que existiam no Brasil, eram precárias, incipientes e sobreviviam em péssimas condições.

Em 1860 até houve uma pequena expansão da indústria algodoeira nacional, em razão das guerras da Secessão nos Estados Unidos (1861-1865) e do Paraguai (1864-1870) na América Latina. Contudo, as políticas governamentais brasileiras nesta época, já eram voltadas ao favorecimento da lavoura cafeeira e seus grupos de interesses. Somente a partir de 1875, quando o Brasil imperial se encontrava em profunda crise econômica é que, segundo Luz (1961), houve o fortalecimento do nacionalismo econômico. Foi o momento da efetiva superação da política do tipo colonial mercantilista, com mais indivíduos e grupos passando a perceber que a economia agrícola apresentava inúmeros obstáculos, necessitando recorrer à indústria como instrumento de crescimento econômico da nação.

Assim, em 1878, o governo imperial elevou a taxa alfandegária para 50\%, nomeou uma comissão para revisar as taxas e atender os interesses tanto da agricultura, quanto do comércio e da indústria. O presidente da Comissão João da Costa Pinto Dantas, filho de Barão, político e proprietário rural, seguindo a carreira do pai, concedeu proteção e acolheu as reivindicações 
das indústrias em 1879, elevando a taxa alfandegária para produtos industriais importados. Essa elevação levou a discussões e desentendimentos, sobretudo, entre os próprios ramos fabris, conforme destaca Luz (1961).

A medida não agradou a todos, mas ajudou a acalmar os ânimos, segundo a autora. Em 1881, foi constituída uma diretoria provisória da Associação Industrial. O líder no Congresso era o industrialista Antônio Felício dos Santos. Compondo a Associação Industrial tinha-se desde representantes de fábricas de tecidos, velas até carpinteiros e alfaiates. Esta heterogeneidade de membros contribuía, segundo Luz (1961), para que não houvesse uma pauta de reivindicações e ações mais unificadas, o que favorecia ao governo resistir em atender as reivindicações dos industrialistas.

De acordo com Luz (1961), apesar de o governo resistir fortemente aos desejos dos industrialistas, a crise da lavoura no final do século XIX e a queda dos preços do café, contribuíriam para o desenvolvimento de uma política industrial na época. Por outro lado, o movimento nacionalista industrialista ampliou seu espaço de ação denunciando os problemas brasileiros, por ser uma nação exclusivamente agrícola e ter sua economia alicerçada em um único produto, o café. Outros elementos que favoreceram este discurso foram: o crescimento da população nas cidades, em razão da imigração e a carência de empregos, bem como a falta de amparo para esta camada do povo. Muitos viviam de esmolas nas ruas, prostituição e roubos, segundo a autora.

Outro defensor do nacional industrialismo foi Duque Estrada. Para ele, esses problemas ocorriam devido à falta de protecionismo às indústrias e a instabilidade das tarifas aduaneiras, que acabavam deixando as populações das cidades à míngua; uma vez que, não se incentivava o trabalho nacional.Sobre a posição da lavoura perante o desenvolvimento industrial, Luz (1961) destaca que os defensores da agricultura argumentavam que não eram totalmente contrários à indústria. $\mathrm{O}$ que não queriam, era uma política protecionista que viesse prejudicar o consumidor.

No entanto, a partir do momento em que a indústria passou a crescer e as dificuldades aumentaram junto à agricultura, novos debates, além de desentendimentos começaram a surgir entre as duas vertentes de pensamento. Outro argumento usado pelos defensores do setor agrícola, era que a indústria seria incompetente para abastecer o mercado nacional. Então, se o governo não tivesse condições para atender as reivindicações dos dois setores, agricultura e indústria, deveria considerar somente os interesses dos agricultores sob o argumento de que eles alimentavam a nação.

Do outro lado, o movimento nacionalista industrialista crescia e criticava, sobretudo, o comércio estrangeiro no Brasil. Essas manifestações nacionalistas vinham, segundo Luz (1961), dos próprios industriais. A crítica era que o comércio importador explorava o consumidor nacional. Assim, começou ganhar corpo e forma, nesse período, o pensamento nacionalista industrializante. Segundo a autora:

[...] Esta observação sobre a drenagem da riqueza nacional para o exterior era um dos fundamentos de um novo argumento que surgia a favor, não só da nacionalização do comércio, como também da industrialização do país - o desequilíbrio da balança de pagamentos, argumento que constituiu, no desenvolvimento do nacionalismo econômico brasileiro, um fator preponderante. (LUZ, 1961, p.58)

De acordo com Luz (1961), com a crise econômica instalada no país, no final do século XIX, era perceptível um ambiente hostil e propício para essas manifestações nacionalistas, fundamentais ao desenvolvimento das práticas protecionistas à indústria. 


\subsection{A ASCENSÃO DO PENSAMENTO NACIONALISTA BRASILEIRO E AS REIVINDICAÇÕES INDUSTRIALISTAS DURANTE A I REPÚBLICA (1889-1930)}

O líder do movimento industrialista nacional no final do século XIX foi, segundo Luz (1961), o médico e industrial Antônio Felício dos Santos. Em 1882, Santos redigiu um manifesto que fora divulgado pela Associação Industrial, no qual dizia não defender nenhuma doutrina econômica, mas condenava aqueles que defendiam a ideia de que o Brasil deveria ser uma nação essencialmente agrícola. Para Santos apud Luz (1961), só existiam pontos positivos na industrialização do Brasil e, por isto, exigia a estabilidade da tarifa aduaneira. $\mathrm{O}$ industrial destacava, ainda, em seu manifesto, o desequilíbrio no balanço de pagamentos e a situação caótica do Império. Santos, segundo a autora, como os demais industrialistas, defendia a industrialização como único instrumento capaz de equilibrar as finanças nacionais. E, para que isso ocorresse, pregava o fim do Império.

Esse pensamento econômico nacionalista industrialista, nas duas primeiras décadas do Brasil republicano pode ser dividido em duas correntes, segundo Luz (1961):

1) Uma liderada por Amaro Cavalcanti (1849-1922), jurista e político que, pelo seu otimismo, entusiasmou os republicanos. Acreditava que as fontes produtoras de riqueza eram constituídas somente pelas atividades industriais, excluindo, assim, todas as outras atividades rentáveis que eram praticadas no Brasil. Para Cavalcanti, segundo Luz (1961), a agricultura não passava de uma fonte precária de renda, dependente das condições climáticas e da mão de obra; uma vez que naquela época, pouca era a utilização de máquinas. Assim, via como indispensável o desenvolvimento industrial do país, sob a proteção do Estado, para que se atingisse o verdadeiro progresso enquanto nação desenvolvida. Segundo Cavalcanti, o pretecionismo à indústria brasileira seria fundamental para:

\footnotetext{
1) dotar o país de indústrias necessárias ou lucrativas, que de outra sorte seriam sufocadas logo ao nascer; 2) assegurar, por êsse modo, trabalho e bem-estar à população operária do país; 3) tornar-se independente do estrangeiro, dispensando-se de comprar-lhe produtos, a respeito dos quais, é de supor, aquêle acabaria por adquirir o monopólio, depois de haver arruinado a indústria nacional. (CAVALCANTI apud LUZ, 1961, p.67-68)
}

Segundo Luz (1961), Cavalcanti defendia o uso do capital estrangeiro para inicialmente fortalecer a indústria e, quando a industrialização estivesse fortalecida, dispensá-lo. Defendia, também, a necessidade da intervenção estatal na economia; afirmando que em muitas situações, ela foi imprescindível; como, por exemplo, na construção das estradas de ferro. Para a autora, o naciosalismo econômico industrializante de Cavalcanti não foi fenômeno isolado naquela época. Outras pessoas também compartilhavam dessas ideias, principalmente na década de 1890, onde se observou que o nacionalismo se tornara mais intenso. O Brasil era um país pobre e muito se discutia sobre isto, pois não se compreendia por quais motivos uma nação que tanto produzia e trabalhava, vivia em constante miséria.

2) A outra corrente de pensamento tinha como principal representante Serzedelo Correia (1858-1932), militar e político cuja defesa do desenvolvimento industrial nacional se dava, segundo a autora, por entender que somente a indústria poderia desenvolver as forças produtivas em países novos como o Brasil, de forma a dar fim a toda e qualquer instabilidade econômica. Correia foi líder do movimento protecionista que ocorreu durante os anos de 1895 a 1905 porque via no protecionismo um instrumento necessário ao desenvolvimento das indústrias que realmente poderiam trazer o progresso para o país.

Outros industrialistas nacionalistas da época defendiam o protecionismo, mas se queixavam do desequilíbrio existente entre os capitais que eram empregados na lavoura e os utilizados na indústria. Aristides de Queiroz, por exemplo, afirmava, segundo Luz (1961), que 
enquanto investia-se 1 centavo na indústria; na lavoura, eram investidos 170. Dessa forma, contribuía-se para o déficit econômico do país; uma vez que, os produtos agrícolas eram essencialmente coloniais. Segundo a autora, na primeira década republicana, a barreira alfandegária não era suficiente para promover o desenvolvimento da indústria nacional. Seriam necessários, também, reduzir os custos de transportes e promover a livre entrada de produtos nacionais de um estado para outro.

A proteção de interesses regionais agrícolas, principalmente dos estados de Minas Gerais e do Rio de Janeiro, paralelo ao industrial, também contribuiu, segundo Luz(1961), para o fortalecimento do movimento em defesa da produção da indústria nacional. Assim, segundo Luz (1961), a partir da proclamação da República, em 1889, firmou-se no pensamento econômico brasileiro, duas correntes industrialistas nacionalistas, opostas entre si quanto aos ideais defendidos:

1) Uma, ligada ao liberalismo econômico, era contra qualquer intervenção estatal ou protecionismo em favor da indústria, acreditando que as indústrias seriam capazes de se desenvolverem sozinhas. Eram as chamadas indústrias naturais, das quais Joaquim Murtinho era defensor, por acreditar que a proteção estatal não deveria ser para todos os setores industriais, mas, somente para os viáveis economicamente. Segundo Murtinho apud Luz (1961), era preciso aumentar a produção do país, sem nenhuma intervenção estatal, vista por ele como moléstia em qualquer setor econômico. Para Murtinho, as riquezas nacionais eram inesgotáveis e abundantes, inclusive em capitais, gerando produção agrícola em larga escala e de forma desordenada. O mesmo teria ocorrido com as indústrias, desenvolvidas de forma artificial, isto é, sem estudos prévios, planejamento e com capital estatal, que, segundo Murtinho, desvalorizavam a produção e prejudicavam o consumidor nacional.

2) A outra corrente, de viés protecionista, tinha Américo Werneck como representante. Werneck questionava a ideia de que a população rural estava sendo sacrificada pelos altíssimos custos da indústria. Defendia o protecionismo tanto para a agricultura, quanto para a indústria, procurando destacar, sempre, a cooperação entre ambos os setores por serem interdependentes. Entretanto, para Werneck, segundo Luz (1961), a terra estava sempre em primeiro plano e se algum setor tivesse que ser sacrificado, este deveria ser o industrial. Neste sentido, segundo a autora, Werneck expressava um ruralismo forte e que se tornou movimento intenso na década de 1920. De acordo com Luz:

\begin{abstract}
“[...] Nos domínios propriamente nacionalistas, o ruralismo, já esboçado no pensamento de Américo Werneck e que se manifesta de modo mais radical em Alberto Tôrres, associava-se a um movimento de protesto ao que se denominava o artificialismo do nosso processo de industrialização, movimento que lentamente foi-se desenvolvendo, à medida que, na política brasileira, os interesses agrícolas foram sendo preteridos pelos do capital, essencialmente urbano, fôsse êle industrial, comercial ou bancário. Habilmente manobrada por interêsses contrários à industrialização do país, essa oposição à indústria nacional atingiu, entretanto, a própria população urbana, consumando, assim, o divórcio entre os sentimentos nacionalistas e o movimento industrial que, paradoxalmente, baseava as suas reivindicações em argumentos nacionalistas e que iniciara a sua campanha e realizara as suas primeiras conquistas apoiado, justamente, nesse nacionalismo... (LUZ, 1961, p. 95)
\end{abstract}

No movimento nacionalista industrializante, a questão do capital estrangeiro nas primeiras décadas do século XX, também, foi motivo de grandes debates entre seus defensores e opositores. Existiam aqueles que eram a favor do capital estrangeiro, considerando-o necessário para o desenvolvimento do país enquanto nação industrial. Do outro lado, estavam os contrários ao uso do capital estrangeiro em determinados setores. Em alguns casos, o capital estrangeiro era visto como vilão porque estaria levando riquezas do Brasil, para o exterior. 
Também entre os defensores da agricultura e anti-industrialistas muitos repudiavam o capital estrangeiro por considerarem que as empresas estrangeiras saqueavam o país tanto na exploração de seus recursos, quanto por meio da exportação de capitais para o exterior.

\subsubsection{As reivindicações industrialistas na Primeira República, (1889-1930)}

De acordo com Luz (1961), observa-se no início da Primeira Republica uma reativação do sentimento nacionalista. A indústria, nesse período, era vista como o único meio capaz de fazer o Brasil progredir e, por isso, todos os capitais empregados no país deveriam ser investidos em novas indústrias. Mas foi um momento de prosperidade que durou pouco, porque foi gerada pelas emissões de papel moeda, que logo virou crise pela política do encilhamento ${ }^{6}$.

Tentando impulsionar a industrialização no país, o presidente da República Deodoro da Fonseca (1889-1891) junto ao ministro da Fazenda Rui Barbosa, adotaram uma política de incentivo à emissão de papel moeda. O intuito era facilitar o crédito aos investidores, mas o que se teve foi a desvalorização da moeda brasileira, o fechamento de inúmeras empresas e indústrias que haviam surgido no contexto. Essa crise, de acordo com a autora, acabou trazendo sérios problemas para as indústrias, que foram apontadas como fraudulentas.

De acordo com Luz (1961), nos primeiros anos da República, a indústria ainda não havia conseguido se firmar, sendo preciso o auxílio direto do governo. Em 1892, já na gestão administrativa do presidente Floriano Peixoto, o Congresso votou uma lei que diminuía 30\% das taxas sobre a importação de máquinas, equipamentos para lavoura, ferramentas aos operários, matérias-primas e demais artigos de uso nas fábricas. Muitas outras concessões privilegiadas ocorreram, havendo, segundo Luz (1961) injustiças e abusos na adoção de isenções fiscais, desfalcando o Tesouro Nacional. Pagas pelos contribuintes, por meio de impostos, os industrialistas desejavam, segundo a autora, que fosse revisada essa tarifa alfandegária pois, segundo eles, o aumento dos impostos encarecia o custo de vida no Rio de Janeiro. Segundo Luz:

Êsse movimento a favor de uma revisão dos direitos alfandegários resultou na pauta de 1896 que foi, entre tôdas as tarifas brasileiras até então decretadas, a que revelou intuitos protecionistas mais acentuados. A comissão encarregada da revisão da tarifa, refletindo o pensamento expresso por Serzedelo Correia, manifestava uma orientação marcadamente, nacionalista e procedeu à reforma tendo em vista dois grandes argumentos a favor de uma determinada política protecionista - da vulnerabilidade de nossa economia baseada na exportação de uns poucos produtos agrícolas e do desiquilíbrio da nossa balança comercial... (LUZ, 1961, p.112)

Os industrialistas defendiam, então, o impulso na produção nacional seja agrícola ou industrial, mas por meio de uma tarifa protetora com maior atenção às indústrias que eram abastecidas de matéria-prima do próprio país. Tinha-se, ainda, os resquícios de outro problema, do final do XIX, representado pela crise do café e o agravamento que a mesma acarretou no plano econômico brasileiro, refletindo diretamente nas questões da indústria nos primeiros anos da República. Em 1897, uma nova tarifa foi decretada, porém, com reduções de taxas. Entretanto, por privilegiar alguns ramos industriais em detrimento a outros, gerou mais descontentamento e insatisfação. Entrava-se em discussão a validade do sacrifício das rendas aduaneiras para manter as indústrias.

\footnotetext{
${ }^{6}$ Crise econômica ocorrida no final do Segundo Reinado, cujos efeitos foram mais sentidos, posteriormente, no Governo Provisório do Marechal Deodoro da Fonseca entre 1889 e 1891. Sobre as reformas de Rui Barbosa ver TOPIK (1987).
} 
Em 1899, segundo Luz (1961), na gestão do presidente Campos Sales (1898-1902), foi nomeada uma comissão para revisar a pauta aduaneira, onde os componentes eram de uma corrente que reconhecia os supostos abusos praticados em nome da proteção à indústria nacional. Ocorreu, assim, uma reforma no Congresso Nacional. O presidente Campos Sales adotou medidas de saneamento financeiro do governo e, em 1900, a nova tarifa fora decretada, tendo como foco a arrecadação eficiente e rentável. Contudo, em 1901, houve uma elevação no valor da moeda, causando desconforto nas indústrias brasileiras e questionamentos acerca das políticas implementadas por Campos Sales. Essa crise evidenciou que o problema do país era, também, financeiro, além da subprodução.

Por isso, de acordo com Luz (1961), formou-se um grande movimento em defesa do estímulo à produção da indústria nacional. Essa forte corrente tomou duas direções: a primeira visava a nacionalização das indústrias brasileiras e a segunda, a proteção dos produtos agropecuários. Em meio a este movimento, foi surgindo no país, uma onda de sentimentos contrários e negativos quanto às indústrias artificiais. Um exemplo de indústria artificial, segundo a autora, foi a de fósforos, uma vez que tudo importava, desde o palito até o papel de embrulho. Ou seja, o único trabalho no Brasil era montar os palitos de fósforo e colocá-los na caixinha. Discussões acerca da necessidade da concessão de direitos às fábricas nacionais para que pudessem produzir mercadorias, que até então eram importadas, foram muitas vezes, repudiadas.

Nas primeiras décadas do século XX, fortaleceu- se o movimento nacionalista industrialista que reivindicava do Governo Federal, mais medidas protecionistas contra os produtos estrangeiros. Para Luz (1961), esse movimento favoreceu não somente as indústrias, como toda a produção nacional. Sem contar que reuniu grandes industrialistas, tais como: Serzedelo Correia, Barata Ribeiro e Osório de Almeida. Por outro lado, São Paulo que até então pouco havia se envolvido na luta a favor da indústria, passou a participar ativamente do movimento protecionista voltado a este setor.

De acordo com Luz (1961), entre 1903 e 1904, ocorreram várias tentativas de revisão da pauta aduaneira, com tendências nacionalistas, visando defender a produção nacional por meio de uma tarifa protecionista. Neste contexto, o deputado mineiro João Luís Alves, propôs, por exemplo, um projeto extremamente nacionalista, onde defendeu uma grande elevação dos direitos sobre os produtos nacionais e, por preconceito à chamada indústria artificial, privilegiou algumas indústrias em detrimento a outras. As indústrias de sua preferência eram as que se utilizavam de matéria-prima nacional, segundo a autora.

O projeto, segundo Luz (1961), não foi aceito pelas oposições regionais. Mas, após muitas discussões no Congresso Nacional sobre os direitos alfandegários serem cobrados em ouro e, em papel moeda, foi decretado que $50 \%$ da cobrança seria realizada em ouro. Esta foi a única forma de se conseguir maior proteção às indústrias naquele momento. No entanto, o aumento dos direitos alfandegários, com a elevação da quota-ouro, acarretou no encarecimento do custo de vida da população brasileira, principalmente, nos centros urbanos maiores, o que descontentou da maioria.

Para o financista da época, Barão D'Anthourad, não somente o protecionismo encareceu o custo de vida, como, também, levou ao aumento das despesas públicas. A partir de 1905, contra a indústria onerosa que acarretou no alto custo de vida, surgiu uma intensa campanha não só da lavoura, mas, também, da população urbana que havia crescido em massa nos primeiros anos da República e que se via afetada com a questão.Versos, cada vez mais frequentes, desmoralizando a indústria surgiram entre as camadas urbanas, principalmente, do Distrito Federal e de São Paulo. Tal oposição reforçava os interesses da agricultura. Contudo, de acordo com Luz (1961), até meados de 1911 observou-se um grande impasse na solução do problema da revisão da pauta aduaneira, além de continuarem os ataques à indústria nacional. 
Segundo Luz (1961), como as alterações dos direitos alfandegários eram constantes, os industrialistas queriam uma tarifa que acabasse com esse problema. Em meados de 1905, criouse a Caixa de Conversão para valorizar o café e estabilizar o câmbio, mas que acabou, também, entrando em discussão entre os industrialistas durante alguns anos. Ocorre que, em 1910, a exportação de produtos nacionais superou a importação fazendo com que, através da Caixa de Conversão, circulasse uma grande quantidade de papel ao invés de ouro, causando inflação. Em 1913, ano que antecedeu ao início da I Guerra Mundial, veio a crise internacional, de cunho fiscal, que baixou os preços dos produtos nacionais. A indústria nacional foi afetada, sendo a de tecidos a mais atingida.

Com o impacto da I Guerra Mundial (1914-1918), a indústria nacional, no entanto, passou a firmar-se e outras surgiram devido à procura por artigos que não estavam sendo fabricados nos países envolvidos no conflito bélico. O estado de São Paulo expandiu o campo industrial, sobretudo, da indústria de tecidos, chapéus e calçados. Houve, ainda, o crescimento dos impostos sobre o consumo aos artigos de fabricação nacional. A população operária também cresceu e serviu, assim, para reforçar a posição política da indústria que crescia. Porém, um embate começaria em meados da década de 1920, entre o comércio importador e a indústria nacional; já que; o primeiro buscava combatê-la a todo custo. Neste contexto, a questão sobre a reforma da tarifa aduaneira voltou em discussão. Em 1915, foi criada no Congresso Nacional, uma comissão mista de deputados, senadores, protecionistas e livre-cambistas para formular um projeto de reforma da tarifa aduaneira. Venceram, segundo a autora, os interesses do Centro Industrial.

Na gestão administrativa do presidente Epitácio Pessoa, em 1919, foi apresentado novo projeto pelo Ministro da Fazenda Homero Batista, que visava a redução dos direitos alfandegários sobre as mercadorias não produzidas no Brasil e que eram difíceis de abastecer em território nacional. Batista defendia, segundo Luz (1961), aquelas indústrias que se utilizavam das matérias-primas nacionais. Prevendo qualquer tipo de negação ou resistência ao projeto, Batista enviou-o para o Congresso já com uma solicitação para ser posto em prática imediatamente. Mas, para Luz (1961), o Ministro esquecera do prestígio político que a indústria nacional havia atingido. Rio de Janeiro e São Paulo não ficaram contentes com as medidas propostas e a reforma ficou engavetada no Senado.

Entre 1920 e 1924, houve uma série de movimentos revolucionários no país, além do custo de vida ter aumentado significativamente. Assim, além dos agricultores, parte da população urbana das grandes cidades passou a se opor às indústrias, acreditando que elas só encareciam o custo de vida. Em face da dificuldade dessa luta pela industrialização, em São Paulo, em 1928, organizou-se um novo Centro para discutir os direitos industriais. Tratava-se, segundo Luz (1961), do Centro das Indústrias de São Paulo, cujo líder era Roberto Simonsen.

No discurso de inauguração do referido Centro, Simonsen esclareceu os fundamentos nacionalistas da política industrial brasileira. Ele procurava, com isto, conciliar os interesses nacionais e os da indústria, por meio de seu conceito de função social. A indústria, de acordo com Simonsen apud Luz (1961), teria responsabilidades sociais com a população, e, esta por sua vez, deveria torcer pela prosperidade das indústrias que seriam, segundo ele, o mesmo que a nação.

De acordo com Lima (1976), Roberto Simonsen foi um dos maiores defensores e coerentes industrialistas que o Brasil já teve. Além de ter impulsionado o setor industrial e outros tipos de empreendimentos, foi um importante líder e técnico da industrialização, tendo uma ação ampliada no campo da economia. Sua atuação foi marcante entre as duas grandes guerras mundiais (1914-1918) e (1939-1945), respectivamente, falecendo em 1948. Escreveu vários manifestos, livros e documentos em defesa da industrialização brasileira. Segundo Simonsen: 
[...] Assim, os brasileiros que combatem a implantação e disseminação das indústrias no país, fazem consciente ou inconscientemente obra a favor das nações estrangeiras, interessadas na conquista de nossos mercados, trabalhando para que retrogrademos à posição de colônia dos produtores estrangeiros, à mercê ainda de um bloqueio econômico em caso de guerra. (SIMONSEN apud LIMA, 1976, p. 161)

Para Lima (1976), Simonsen não poderia ser mais claro a respeito do seu posicionamento quanto ao papel da indústria na economia brasileira tanto em relação ao mercado interno, quanto externo. Era protecionista afirmando que embora o protecionismo pudesse cercear, por algum tempo, o intercâmbio entre países, no geral, traduzia-se em uma forma de liberdade de produção dentro das nações que adotavam esta política.

Para Simonsen apud Lima (1976), os países que adotavam políticas protecionistas estavam, ao mesmo tempo, oferecendo a qualquer um dos seus cidadãos, condições para montar a própria indústria no ramo que desejasse e, de maneira sadia, proteção ao seu negócio contra dumpings ou outras possíveis manobras que seus concorrentes estrangeiros pudessem utilizar. Além da sua atuação prática, Simonsen deixou ao país um grande legado intelectual materializado em várias obras que tratavam, inclusive, sobre a formação econômica do Brasil. (LIMA, 1976)

Sobre a política industrial no Brasil entre 1880-1930, Luz (1961) destaca cinco momentos importantes: 1) política de amparo, visando a produção nacional e o aproveitamento dos recursos naturais do país; 2) tentativas de oposição ao industrialismo implantado pela República durante o período de 1891 a 1898 ; 3) a vitória na primeira década do século XX, da política fiscal favorável a indústria; 4) manutenção do câmbio com taxas baixas e a cobrança, em ouro, dos direitos de importação e; 5) tentativa de se inaugurar um novo industrialismo a partir de 1910, alicerçado nas indústrias básicas.

A autora conclui sua obra, enfatizando a ideia de que os movimentos nacionalistas industrialistas vigentes no Brasil colonial até parte do Segundo Reinado não conseguiram resultados positivos significativos, em razão dos fortes interesses ingleses no Brasil e da política fiscal nacional que favorecia, de forma ampla e irrestrita, os interesses agrários, denominados por Luz (1961) de "lavoura", pois estes seriam quem dirigiam, de fato, os destinos nacionais. A partir de 1875, sob os argumentos a respeito da necessidade de se equilibrar o balanço de pagamentos, os grupos de interesses ligados à indústria, passaram a ganhar espaço. Complementarmente a este discurso, têm-se, também, as reivindicações nacionalistas contra o comércio estrangeiro, as crises agrícolas e a baixa renda nacional, levando, o Governo Central, paulatinamente, direcionar políticas voltadas ao amparo da produção incluindo a industrial.

Para Luz (1961), apesar de terem apresentado falhas e, muitas vezes, se mostrarem parcas e incipientes; as políticas, bem como, as atuações dos grupos ligados aos movimentos nacionalistas industrializantes desenvolvidos no Brasil, no período analisado, seus resultados não devem ser menosprezados. Estas ações, segundo a autora, não significaram apenas as primeiras tentativas de se promover, de fato, a industrialização no país. Representam, principalmente sementes que germinaram e contribuiriam de forma expressiva para $o$ desenvolvimento socioeconômico do Brasil.

\section{CONSIDERAÇÕES FINAIS}

Em “A luta pela industrialização do Brasil (1808 a 1930)", a autora Nícia Vilela Luz mostra, a partir de uma vasta quantidade de fontes primárias e secundárias, contendo expressivos dados qualitativos e quantitativos, que no Brasil sempre existiram grupos de 
interesses ligados à defesa da indústria e da industrialização. A autora destaca que desde o período colonial até 1930, não importando o regime ou forma de governo, observou-se a existência de uma mentalidade industrialista, representada por indivíduos e grupos dispostos a lutar e buscar o amparo governamental para o desenvolvimento do setor industrial. Ressalta, ainda, que ao longo do período analisado, a tarifa aduaneira foi o instrumento protecionista mais utilizado pelos governos.

Em épocas de crise, segundo Luz, os industrialistas buscavam, também, subsídios financeiros evocando, sempre, a necessidade da indústria receber benefícios iguais ou superiores aos ofertados ao setor agrícola, sob a argumentação de que a industrialização seria capaz de colocar o país no rol das nações desenvolvidas. Contudo, suas reivindicações, na maioria das vezes, não eram satisfeitas, sobretudo, quando se tratava da pauta alfandegária; sempre instável e motivo de grandes controvérsias entre governos e os grupos de interesses tanto agrários, quanto industriais. Em geral, a "lavoura," como se refere a autora ao setor agrícola, saía vitoriosa. Esta situação passou a mostrar mudanças importantes somente a partir de 1875, quando a crise agrária, de fato, colocou em xeque o poder da agricultora gerar renda interna suficiente para resolver os constantes problemas da economia brasileira, não somente no tocante ao desemprego, mas também, dos constantes déficits no balanço de pagamento.

Assim, os discursos sobre a necessidade de se industrializar o país, bem como, sobre a capacidade da indústria cumprir melhor o papel de setor gerador de renda interna para cobrir tais déficits, passaram a fazer parte da pauta e das ações constantes dos nacionalistas industrialistas, sobretudo, durante a Primeira República (1889-1930). Foram movimentos que, embora naquela época não tenham surtido os resultados esperados, representaram a construção dos pilares do que viria a ser setor industrial brasileiro.

\section{REFERÊNCIAS}

LIMA, H. F. História do pensamento econômico no Brasil. São Paulo: Companhia Editora Nacional, 1976.

LUZ, N. V. A luta pela industrialização do Brasil (1808-1930). São Paulo: Difusão Europeia do Livro, 1961.

Inquietação revolucionária no Sul: a Conjuração Mineira. In: LINHARES, M. Y. e S.; TEIXEIRA, F. C. História Geral da Civilização Brasileira. São Paulo: Brasiliense, 1981. Tomo I.

As tentativas de industrialização no Brasil. In: HOLANDA, S. B. de. OBrasil Monárquico: declino e queda do Império. 5. ed. Rio de Janeiro: Bertrand Brasil S. A, 4 Vol. Coleção História Geral da Civilização Brasileira, 1995.

Amazônia para os negros americanos. Rio de Janeiro: Saga, 1968

RIBEIRO, M. A. R. As primeiras pesquisadoras brasileiras em história econômica e a construção da disciplina no Brasil. História Econômica \& História de Empresas. (1999), n.2, v.2, 6 jul 2012, p.7- 40. Disponível em: www.hehe.org.br/index.php/rabphe. Acesso em: 05 maio 2020. 
TOPIK, S. A presença do estado na economia política do Brasil (1889-1930). Rio de Janeiro: Record, 1987.

O ESTADO DE SÃO PAULO. Uma mulher ganhou o prêmio "Fábio Prado". O Estado de São Paulo. São Paulo, edição de 27 de julho de 1962. p.38. Disponível em <https://acervo.estadao.com.br/pagina/\#!/19620727-26766-nac-0038-fem-6-not > Acesso em 04 de agosto de 2019.

Recebido: 06/07/2020

Aceito: $14 / 04 / 2021$

Publicado: Agosto de 2021 